\title{
Juvenile social play and yearling behavior and reproductive success in female Belding's ground squirrels
}

\author{
Scott Nunes
}

Received: 18 February 2014/ Accepted: 5 April 2014/Published online: 26 April 2014

(C) Japan Ethological Society and Springer Japan 2014

\begin{abstract}
Benefits of play behavior have been described for individuals during the juvenile period; however, it is less clear whether benefits of juvenile play commonly extend beyond the period of juvenile development. I evaluated possible associations between juvenile social play and yearling maternal territorial behavior and reproductive success in female Belding's ground squirrels (Urocitellus beldingi). Higher rates of juvenile social play were associated with greater intensity of territorial aggressive and vigilant behavior during gestation but not later phases of the yearling reproductive cycle, suggesting that both juvenile play and later experience may influence maternal territorial behavior in yearling females. Juvenile social play was also a reliable predictor of whether a yearling female successfully weaned a litter, raising the possibility that juvenile play behavior influences yearling reproductive success via effects on maternal territorial behavior in female $U$. beldingi. Other factors were also related to reproductive success in yearling females. Body mass at the beginning of the yearling reproductive period was not correlated with juvenile social play but was associated with the likelihood of successfully weaning a litter. Yearling females whose mother was still alive were more likely to wean a litter than those whose mother was not alive. Mothers and yearling daughters tended to have maternal territories near each other, and mothers with a surviving yearling daughter expressed aggressive behavior at elevated rates and directed aggression toward intruders on the daughter's territory. Overall, results of the study suggest that juvenile social play is among the variables that
\end{abstract}

S. Nunes $(\bowtie)$

Department of Biology, University of San Francisco, 2130

Fulton Street, San Francisco, CA 94117, USA

e-mail: nunes@usfca.edu influence maternal territorial behavior and reproductive success in yearling female $U$. beldingi, and are consistent with the idea that juvenile play has benefits beyond the juvenile period for female $U$. beldingi.

Keywords Belding's ground squirrel $\cdot$ Maternal behavior - Reproductive success - Social play · Territorial behavior · Urocitellus beldingi

\section{Introduction}

Play is a characteristic behavior of mammals, occurring in young of nearly all mammalian species (Fagen 1981; Bekoff and Byers 1998; Burghardt 2005). Play behavior is generally categorized as social play, involving interactions with conspecifics, or non-social play, involving locomotion or manipulation of objects (Burghardt 2011). Various adaptive functions have been proposed for play behavior in young animals including the promotion of motor, cognitive, and social development, and acquisition of behavioral plasticity in responses to unfamiliar situations (Bekoff 1972, 1988; Poirier and Smith 1974; Bekoff and Byers 1998; Lewis 2000; Špinka et al. 2001). The expression of play behavior may be sexually dimorphic within species, suggesting in some cases that play may have different functions for males and females (Olioff and Stewart 1978; Meder 1990; Pedersen et al. 1990; Pellis et al. 1996; Nunes et al. 1999; Maestripieri and Ross 2004; Paukner and Suomi 2008; Auger and Olesen 2009). Play behavior is associated with improved motor skill and coordination during the juvenile period in Belding's ground squirrels (Urocitellus beldingi; Nunes et al. 2004a, b). Here I evaluated possible benefits of play behavior beyond the juvenile period in female $U$. beldingi. 
Play behavior is related to a variety of benefits to young animals while they are juveniles. For example, higher rates of play among young horses (Equus caballus) are associated with enhanced body condition and greater survival during the juvenile period (Cameron et al. 2008). Play behavior also improves juvenile survival in brown bears (Ursus arctos; Fagen and Fagen 2004). Play-related improvements in motor skill and coordination in juvenile male $U$. beldingi are associated with early dispersal from the natal area (Nunes et al. 2004a). In red foxes (Vulpes vulpes) social play facilitates the establishment and maintenance of dominance relationships among juveniles (Meyer and Weber 1996), and in common seals (Phoca vitulina) social play behavior helps young animals become integrated into their social groups (Wilson 1974). Moreover, Thompson (1996) suggested that social play in sable antelope (Hippotragus niger) allows young animals to assess their physical and behavioral development relative to that of their peers.

Adaptive benefits of play behavior to individuals beyond the juvenile period are less clear than benefits during early development. However, some studies suggest that the benefits of juvenile play may extend into adulthood. Juvenile play behavior improves long-term survival in $U$. arctos (Fagen and Fagen 2009). Moreover, social play during the juvenile period has been proposed to influence adult social interactions and behavior. For example, it has been suggested that features of juvenile social play reflect adult social roles (Maestripieri and Ross 2004), and that juvenile social play helps forge social relationships that will be important later in life (Rho et al. 2007; Ward et al. 2008). Blumstein et al. (2013) observed that in yellowbellied marmots (Marmota flaviventris) dominance relationships established during play interactions early in life persist into adulthood. It has also been suggested that juvenile social play functions to refine motor skills and behaviors that are important in adulthood. Social play is often similar to adult aggressive and mating behaviors (e.g., Hass and Jenni 1993; Nunes et al. 1999; Pasztor et al. 2001), and has been hypothesized to serve as practice for these behaviors or promote their neurobehavioral maturation (Caro 1988; Byers and Walker 1995). For example, in rats (Rattus norvegicus) juvenile social play has a critical role in shaping adult expression of agonistic and sexual behaviors and emotional responses associated with these behaviors (Hol et al. 1999; van den Berg et al. 1999).

Here I evaluated whether juvenile social play in female $U$. beldingi is associated with the later expression of behaviors important in defending a maternal territory. Infanticide by conspecifics is common in mammalian species, including $U$. beldingi, and female mammals typically have strategies to defend young against this threat (Hrdy 1979; Sherman 1981b). Female $U$. beldingi establish maternal territories during gestation and defend the territories throughout lactation, aggressively evicting intruders who wander onto a territory (Nunes et al. 2000). I observed the social play behavior of female $U$. belding $i$ as juveniles, and later observed maternal territorial behaviors of the same females as yearlings. I evaluated whether rates and intensities of aggressive and vigilant behavior associated with defending territories were correlated with juvenile play.

I further evaluated whether juvenile social play is related to the likelihood of yearling female $U$. beldingi successfully weaning a litter. Female $U$. beldingi may begin reproducing as yearlings; however, on average $35 \%$ of yearling females do not successfully wean a litter (Sherman and Morton 1984). I also evaluated whether body mass at the beginning of the yearling reproductive cycle influenced the chances of successfully reproducing. Reproduction, and in particular lactation, is energetically expensive for female mammals (Kenagy et al. 1989). Some juvenile $U$. beldingi, especially those born later in the active season, fall short of achieving mature body size before entering hibernation (Morton et al. 1974). Thus, as yearlings, females may need to channel energy toward growth, limiting the amount of energy available for reproduction. Play has been shown to be associated with heightened body condition in young animals (Cameron et al. 2008), and hence might influence yearling reproductive success via effects on physical condition and body mass. Finally, I assessed whether having a surviving mother influences reproductive success in yearling female $U$. beldingi. Closely related female $U$. belding $i$ act cooperatively in defending maternal territories (Sherman 1981a), and experience raising young is associated with increased intensity of aggressive and vigilant behavior in defending territories (Nunes 2014). Thus, having assistance from an experienced mother in defending a territory might enhance overall protection of young and improve the chances of successfully weaning a litter in yearling female $U$. beldingi.

\section{Materials and methods}

From May through August 2001-2006 and May through July 2012-2013 a population of $U$. belding $i$ was studied in a 50-ha meadow near Tioga Pass in Mono County, CA, USA $\left(37^{\circ} 55^{\prime} \mathrm{N}, 119^{\circ} 15^{\prime} \mathrm{W}\right)$. This species is diurnal and inhabits alpine and subalpine meadows in the western United States. Squirrels hibernate 8-9 months each year from late summer through spring. Males do not begin breeding until they are 2 years old, whereas females may begin breeding as yearlings (Jenkens and Eshelman 1984). Females typically enter estrus within a week after emerging from hibernation and mate on only 1 day per year, thus bearing at most one litter per year (Morton and Gallup 
1975). Young remain underground in natal burrows during lactation and first emerge from the natal burrow when they are about 25-28 days old, near the time of weaning (Holekamp et al. 1984). Reproductive females maintain maternal territories during gestation, lactation, and the period in which young first emerge from the natal burrow (Nunes et al. 2000). Juveniles engage in play behavior during their first 2 weeks above ground, after which rates of play decline substantially as juveniles roam farther from the natal burrow. Most play interactions ( $>97 \%$ ) occur between littermates (Nunes et al. 1999). All surviving males emigrate from the natal area before reproducing, whereas females tend to be philopatric and remain in their natal areas throughout their lives (Holekamp 1984).

Squirrels were captured in live-traps (Tomahawk LiveTrap Company, Hazelhurst, WI, USA) baited with peanut butter. Traps were checked every $30 \mathrm{~min}$ or less during trapping sessions. At their first capture, squirrels were fitted with monel metal ear tags (National Band and Tag Co., Newport, KY, USA) for permanent identification. The fur of squirrels was marked with unique symbols using hair dye (Clairol, Stamford, CT, USA) to aid in visual identification of individuals during behavioral observations. Body mass of squirrels was measured with spring balance scales (Avinet, Dryden, NY, USA). Females were observed daily throughout the day (0730-1800 h) from elevated posts such as boulders or hilltops to locate their maternal territories. Behavioral cues used to identify maternal territories included excavation of burrows, carrying of nest material into burrows, and initiation of aggressive interactions with conspecifics (Nunes et al. 1997, 2000). Maternal burrows of reproductive females were identified as the burrow that a female first emerged from in the morning or last entered in the evening. After their location was determined, maternal territories of lactating females were observed daily to determine the dates on which their young first emerged from the maternal burrow. Young were trapped within 2 days of their first appearance above ground during which time they remain close to the natal burrow and can be unambiguously assigned to mothers (Holekamp 1984). Adult females in the study were classified as multiparous if they had successfully weaned a litter in an earlier year. Distances between maternal burrows of reproductive females were determined using aerial photographs obtained from the United States Geological Survey. All work with $U$. beldingi in this study followed humane guidelines published for mammals (Sikes et al. 2011).

\section{Behavioral observations}

The behavior of juvenile $U$. beldingi from 87 litters was observed during the summers of 2001, 2002, 2004, and 2012. A total of 81 females from these litters were included in the study as yearlings. The juvenile behavior of these 81 females was observed for an average of $537.7 \pm 29.1 \mathrm{~min}$ over an average of $8.0 \pm 0.4$ days. Behavioral observations of juveniles were conducted throughout the day between 0700 and $1800 \mathrm{~h}$ from elevated posts such as boulders or hilltops. Juveniles were observed during the 2-week period following their first emergence from the natal burrow. During observations, all occurrences of social play behavior were recorded. Rates of social play were calculated for individuals as the number of social play interactions per hour of observation. Specific play behaviors are based on descriptions by Nunes et al. (1999) and are described below.

\section{Social play behavior}

Wrestling the juvenile faces a partner, typically in a ventrum to ventrum clench or embrace, and pecks at the partner's neck, throat, cheeks, or abdomen without inflicting bite wounds.

Tackling the juvenile jumps or pounces on a partner, usually from a running start.

Boxing the juvenile bats with the forepaws at a partner, who usually reciprocates.

Chasing the juvenile follows and pursues a partner while both juveniles are running.

Mounting and play copulation the juvenile climbs on the back of a partner and places the forepaws around the partner's chest or abdomen, grasping in the mouth the skin of the partner's neck, cheek, or back, and aligning the pelvis with the partner's pelvis; the juvenile and partner typically both lie on their sides on the ground; no intromission occurs.

During the summers of 2002-2006, the behavior of reproductive females was observed during gestation, lactation, and the week-long period after emergence from the natal burrow in a total sample of 82 adult and 32 yearling females who weaned litters. Females were observed for an average of $149.8 \pm 5.9 \mathrm{~min}$ during gestation, $141.3 \pm 5.2 \mathrm{~min}$ during lactation, and $88.4 \pm 4.8 \mathrm{~min}$ during the post-emergence period. Behavioral surveys were conducted between 0700 and $1830 \mathrm{~h}$ from elevated posts such as rocks or hilltops. During behavioral surveys, all occurrences of aggressive and vigilant behavior were recorded. Vigilant behaviors included actions with the potential to gather information for the assessment of risks posed by conspecifics, predators, or other threats. Aggressive behaviors included actions with the potential to evict conspecifics or predators from maternal territories. Specific behaviors are based on prior descriptions of behavior in $U$. beldingi (Nunes et al. 2000) and are described below. 


\section{Aggressive behavior}

Threat the squirrel orients toward or rapidly approaches another squirrel, chatters its teeth, holds its tail upright, and twitches its tail with the fur erect.

Chase the squirrel approaches another squirrel in a threat position and runs after it when it moves away.

Attack the squirrel approaches another squirrel in a threat position, pounces or lunges at it and inflicts a bite wound on its rump, flank, chest, neck, or head.

Fight the squirrel faces another squirrel, usually in a ventrum to ventrum clench, and inflicts bite wounds on the chest, neck, or cheeks of the other squirrel.

\section{Vigilant behavior}

Rest alert the squirrel is positioned with all four legs on the ground and its head elevated; the squirrel's body may also be elevated.

Post the squirrel stands on its hind legs with its back erect or semi-erect and forelimbs off the ground.

At least three surveys were conducted for each female during gestation, at least three during lactation, and at least two during the post-emergence period. Focal animals were observed for 30-60 min during each survey. Surveys were occasionally terminated early when females wandered out of site or retreated down burrows. Rates of behavior were calculated for individuals as the number of occurrences of behavior per hour of observation.

To estimate the intensity of aggressive and vigilant behavior, I assigned scores to specific behaviors, with values increasing as the intensity level of behavior increased (Nunes 2014). The intensity of aggressive behavior was considered to increase as it increased the likelihood that a conspecific or predator such as a weasel would be evicted from the maternal territory. Intensity scores for aggressive behavior were assigned as follows: threat, 1 ; short chase $(\leq 5 \mathrm{~m}), 2$; intermediate chase ( $>5 \mathrm{~m}$ but $\leq 15 \mathrm{~m}), 3$; long chase $(>15 \mathrm{~m}$ but $\leq 30 \mathrm{~m})$, 4 ; very long chase $(>30 \mathrm{~m}), 5$; attack or fight, 5 . The intensity of vigilant behavior was considered to increase as it enhanced the potential for assessing risk. Intensity scores for vigilant behavior were assigned as follows: resting alert, 1; posting, 3. An additional point was added to a vigilance score if the behavior occurred on an elevated post such as a rock or fallen tree.

\section{Statistical analysis}

Variables evaluated in the study included body mass, social play behavior of juvenile females, and rates and intensities of vigilant and aggressive behavior of yearling and adult females. Body mass data followed the normal distribution (Lilliefors test, $P>0.05$ ), but behavioral data did not and so were $\log$ transformed to values that were normally distributed (transformed value $=\ln$ [original value]). Multiple linear regression with forward stepping was used to evaluate associations between juvenile social play behavior and rates and intensities of vigilant and aggressive behavior among reproductive yearling females. Discriminant analysis with forward stepping was used to evaluate whether juvenile social play behavior and body mass early in the yearling reproductive period were reliable predictors of whether a yearling female would successfully wean a litter. I used $\chi^{2}$ tests to assess whether yearling females who had a surviving mother were more likely to wean a litter than yearling females who did not. Discriminant analysis with forward stepping was used to evaluate associations between rates and intensities of aggressive behavior in adult females and whether they had a surviving yearling daughter. Independent $t$ tests were used to compare body mass and behavior between specific groups of females. Assumptions of homoscedasticity were met in $t$-tests (Levene's test, $P \geq 0.05$ ). Independent variables in multiple regression and discriminant analysis were checked for multicollinearity with Pearson's $r$. Statistical tests were performed with Systat 13 (Systat Software, Inc., Chicago, IL, USA). For ease of interpretation, values of variables prior to transformation are presented in figures. Mean values are presented \pm 1 SEM. Probabilities were considered significant when $P \leq 0.05$.

\section{Results}

I used multiple linear regression to evaluate the relationship between rates of social play as a juvenile and rates and intensity of vigilant and aggressive behavior during gestation, lactation, and emergence of young from the natal burrow among yearling female $U$. beldingi who successfully weaned a litter. The independent variables in this analysis did not show multicollinearity $(-0.26<r<0.37$, $n=96$ ). Rates of neither aggressive nor vigilant behavior as a yearling mother were related to juvenile social play. However, there was a significant association between juvenile social play and the intensity of aggressive (Fig. 1a, $\left.R^{2}=0.14, F_{1,30}=4.77, P=0.037\right)$ and vigilant behavior (Fig. $1 \mathrm{~b}, \quad R^{2}=0.24, \quad F_{1,30}=9.62, \quad P=0.004$ ) during gestation in yearling females, but not during other phases of the reproductive period. The intensity of both vigilance and aggression during gestation as a yearling tended to increase with rates of social play as a juvenile (Fig. 1).

I also evaluated whether success in weaning a litter among yearling female $U$. beldingi was associated with rates of juvenile social play behavior, body mass at the 


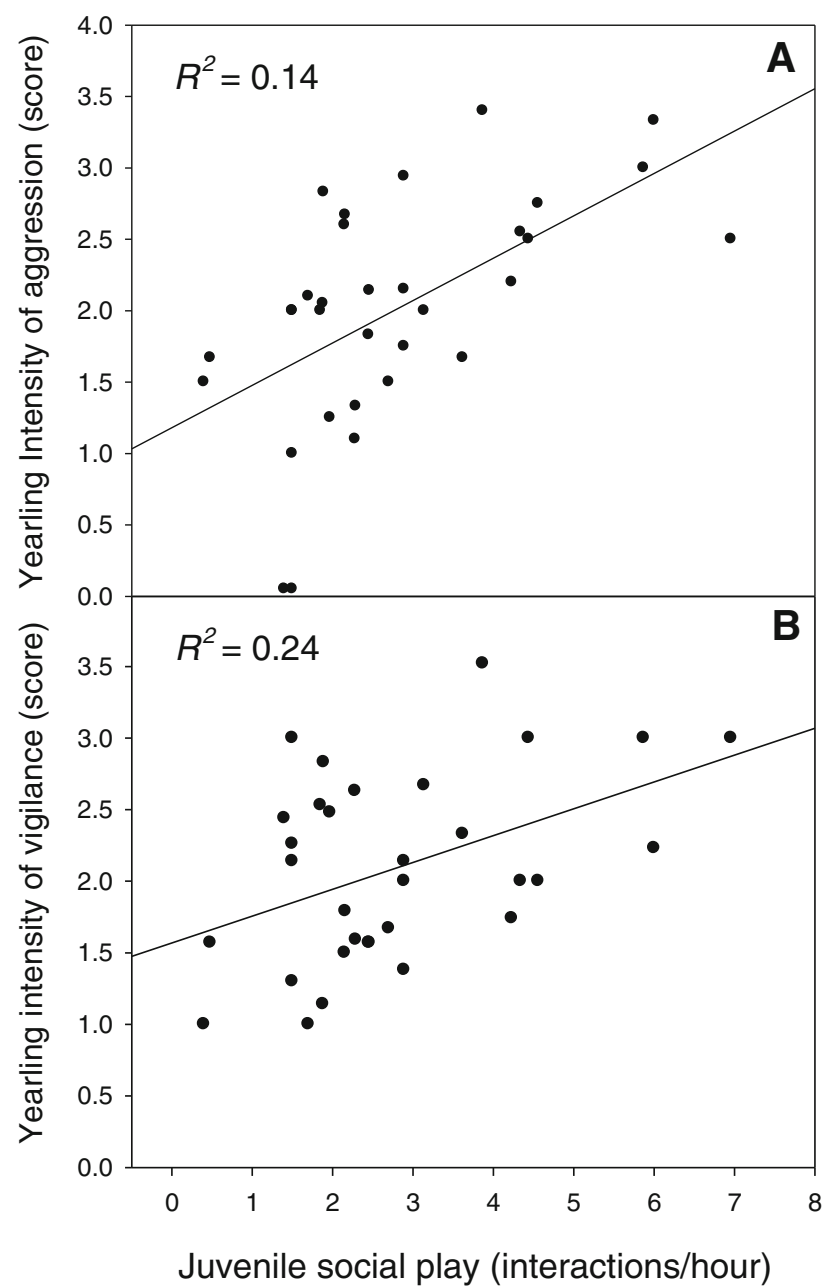

Fig. 1 Association between social play behavior as a juvenile and the intensity of $\mathbf{a}$ aggressive and $\mathbf{b}$ vigilant behavior during gestation among reproductive female $U$. beldingi during the yearling active period. The sample included 32 females

beginning of the reproductive period, or having a surviving mother. Discriminant analysis indicated that both rates of juvenile social play $\left(F_{1,79}=14.08, P<0.001\right)$ and body mass at the beginning of the reproductive period $\left(F_{1,78}=15.63, P<0.001\right)$ were reliable predictors of whether female $U$. beldingi weaned a litter as a yearling. Yearling females who weaned a litter had higher rates of social play as a juvenile (Fig. 2a, $\left.t_{79}=3.75, P<0.001\right)$ and higher body mass at the beginning of the reproductive period (Fig. $2 \mathrm{~b}, t_{79}=3.79$, $P<0.001)$ than did yearling females who were unsuccessful in weaning a litter. I did not observe a significant correlation between rates of juvenile social play and body mass at the beginning of the yearling reproductive period ( $r=0.06, n=81$ ). Rates of social play as a juvenile did not differ between yearling females who did and did not have a surviving mother.
Having a surviving mother was also associated with increased likelihood of weaning a litter. A total of $64.1 \%$ $(25 / 39)$ of yearling females in the study whose mother was alive weaned a litter, whereas only $21.4 \%$ (9/42) of yearling females whose mother was not alive weaned a litter (Fig. 2c, $\chi_{1}^{2}=15.12, P<0.001$ ). The maternal territories of yearling females tended to be near those of their surviving mothers, with the mean distance between the maternal burrows of yearling females and their mothers being $18.3 \pm 2.3 \mathrm{~m}(n=32)$.

I assessed whether the behavior of adult females across the reproductive period was associated with whether they had a surviving yearling daughter. Only adult females who weaned a litter during the current summer were included in this analysis, and adult females with a surviving yearling daughter were included only if their daughter also weaned a litter. Because prior experience raising young can influence aggressive and vigilant behavior in maternal $U$. beldingi (Nunes 2014), only multiparous adult females were included in this analysis. Behavioral variables in this analysis did not exhibit multicollinearity $(0.01<r<0.38$, $n=82$ ). Discriminant analysis indicated that rates of aggressive behavior among adult female $U$. belding $i$ were significantly associated with whether they had a reproductive yearling daughter $\left(F_{1,80}=5.55, P=0.021\right)$, but rates of vigilant behavior and the intensity of aggressive and vigilant behavior were not. In particular, adult females with a yearling daughter had significantly greater rates of aggressive behavior than those who did not (Fig. 3, $\left.t_{80}=2.36, P=0.021\right)$. The mean distance between the maternal burrows of adult females and their yearling daughters in this analysis was $16.3 \pm 1.8 \mathrm{~m}(n=20)$. All 20 females with a reproductive yearling daughter were observed to initiate aggressive interactions toward conspecifics within $5 \mathrm{~m}$ of the daughter's maternal burrow, and $15.9 \%$ (48/301) of aggressive interactions initiated by these females were initiated within $5 \mathrm{~m}$ of the daughter's maternal burrow.

\section{Discussion}

I observed a correlation between juvenile social play behavior in female $U$. beldingi and the intensity of territorial aggressive and vigilant behaviors during gestation in the yearling reproductive period. Females who engaged in social play at higher rates as juveniles also tended to express greater intensity of aggressive and vigilant behavior early in the yearling reproductive cycle. This result is consistent with the idea that play behavior provides training for maternal territorial behavior in young females. However, correlations between juvenile play and yearling behavior did not persist beyond gestation in the 


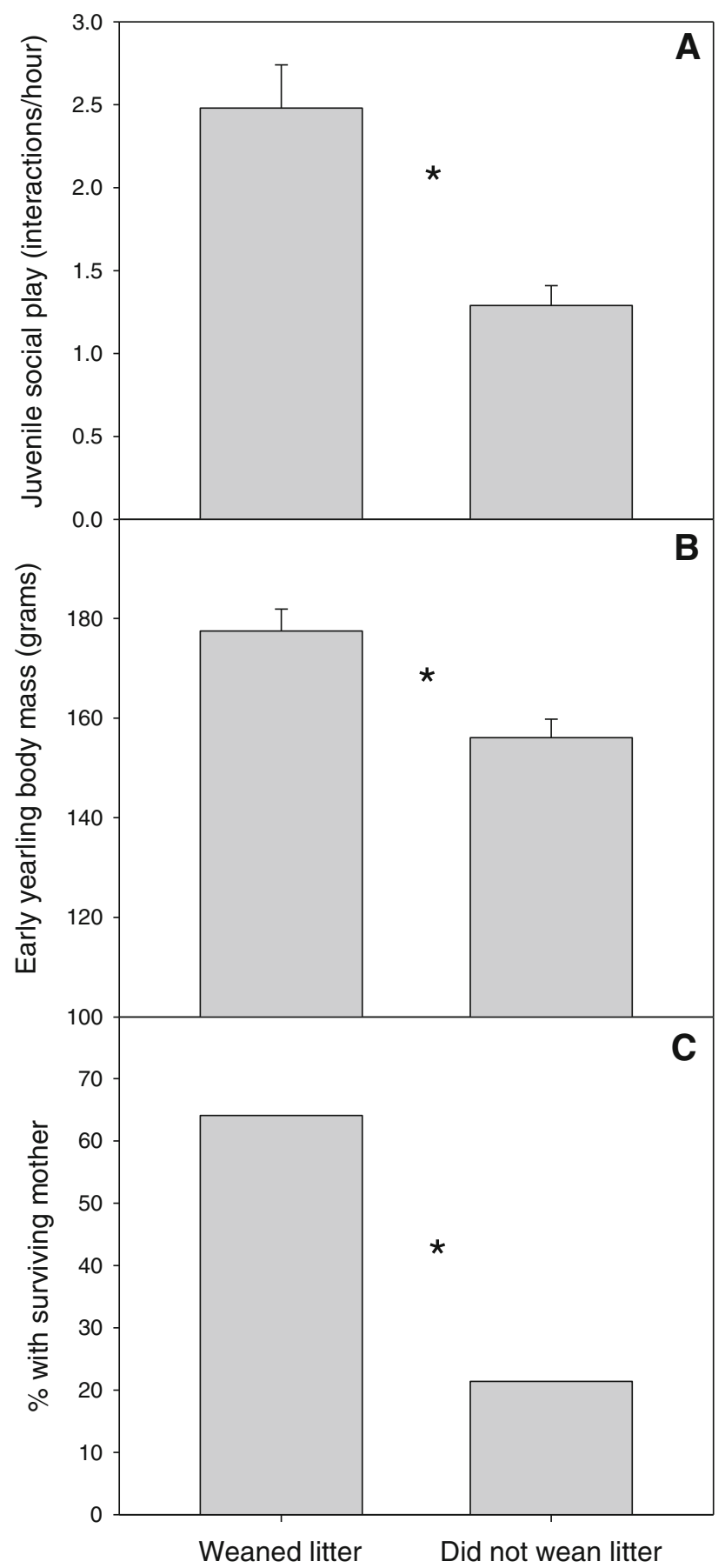

Fig. 2 Comparison between yearling female $U$. belding $i$ who did and did not wean a litter in a rates of social play as a juvenile, $\mathbf{b}$ body mass at the beginning of the reproductive period, and $\mathbf{c}$ whether the female's mother was still alive. Asterisks indicate significant differences between groups of females. The sample included 39 yearling females who weaned a litter and 42 who did not

yearling reproductive cycle, suggesting that experience may also refine the expression of maternal territorial behavior. Nunes (2014) observed that experience raising young is associated with increased intensity of maternal

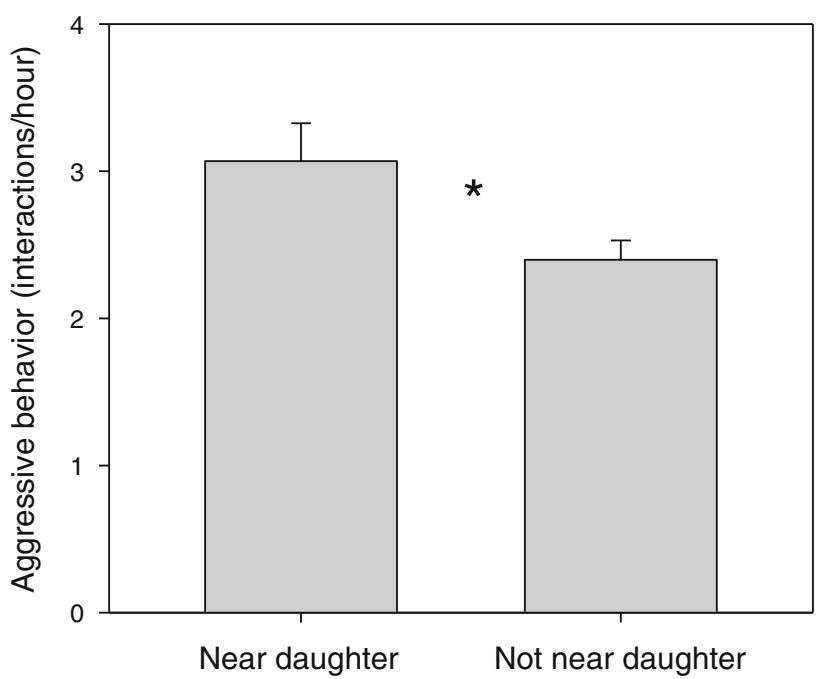

Fig. 3 Aggressive behavior during the reproductive period of adult female $U$. belding $i$ with and without a reproductive yearling daughter nearby. The asterisk indicates a significant difference between groups of females. The sample included 20 adult females with a yearling daughter and 62 adult females without a yearling daughter

territorial behaviors as well as greater accuracy in assessing potential threats on maternal territories.

The association between juvenile play and yearling behavior in this study was somewhat limited. Some studies have failed to indicate distinct associations between juvenile play and later behavior. For example, in meerkats (Suricata suricatta) the social play of young animals was not related to the expression of aggressive behavior or success in winning fights later in life (Sharpe and Cherry 2003; Sharpe 2005). Caro (1988) noted that in various species juvenile play typically comprises a small portion of a young animal's time and energy budgets, and suggested that in some cases juvenile play might be associated with relatively low costs and small improvements or subtle refinements in adult behavior. However, in some species the costs associated with play behavior are substantial, suggesting that the long-term benefits or consequences of play might also be substantial. For example, peaks in social play and social connectivity coincide with peaks in disease transmission and mortality in young chimpanzees (Pan troglodytes), and ontogenetic changes in play behavior have been suggested to underlie predictable cycles of infant and juvenile mortality in this species (Kuehl et al. 2008). Overall, the functional consequences of play during and beyond the juvenile period as well as the costs of play may vary broadly among species, reflecting divergent evolutionary pathways across taxa (Burghardt 2005; Pellis and Pellis 2009).

Although the relationship between juvenile play and yearling behavior in this study may have been limited, it appears to have influenced reproductive success in yearling 
female $U$. beldingi. Rates of juvenile social play were higher among yearling females who successfully weaned a litter compared to those who did not. Greater body mass at the beginning of the active period was also associated with a higher likelihood of successfully weaning a litter among yearling females. Thus, juvenile social play may have influenced yearling reproductive success via effects on body mass and body condition rather than effects on yearling behavior. However, juvenile social play was not correlated with body mass of yearling females at the beginning of the active period, so I believe this unlikely.

Greater intensity of aggressive and vigilant behavior during gestation may better equip yearling females to establish a maternal territory. Nunes et al. (1997) observed that female $U$. beldingi compete for territorial sites at the beginning of the reproductive period and suggested that yearling females might generally be less successful at establishing a maternal territory than are older females. Greater intensity or proficiency in aggressive behavior might confer an advantage to yearling females in establishing a maternal territory and thus successfully weaning a litter. Moreover, reproductive success as a yearling might increase overall lifetime reproductive success. Sherman and Morton (1984) observed that weaning a litter as a yearling does not adversely affect survival or future life expectancy in female $U$. beldingi.

Although juvenile social play may influence reproductive success in yearling female $U$. beldingi, other factors may also have a notable impact on reproductive success. Yearling female $U$. beldingi in this study were more likely to wean a litter if their mother were still alive. Mothers and yearling daughters tended to have maternal territories in close proximity to each other. Mothers with a surviving yearling daughter exhibited elevated overall rates of aggression and directed aggressive behavior to intruders on the daughter's territory. Sherman (1981a) similarly observed that closely related female $U$. belding $i$ often have contiguous territories and assist each other in evicting intruders from the territories.

Associations between juvenile social play and behavior beyond the juvenile period may be related to influences of play on the brain. Byers and Walker (1995) suggested that juvenile play might influence proficiency of adult behavior via effects on late-developing structures involved in motor function, such as the cerebellum. Moreover, social play behavior is associated with synaptic remodeling and increased growth factor expression in specific brain regions (Cooke and Shukla 2011), and social play and peer interaction in juvenile male rats can prevent deficits in adult sexual behavior associated with lesions to the medial preoptic area of the hypothalamus (Twiggs et al. 1978; Leedy et al. 1980). Also in rats, juvenile social play influences dendritic arborization in the medial prefrontal cortex, possibly to promote development of motor responses. Juvenile social play along with other social interactions also influences dendritic arborization in the orbitofrontal cortex, possibly to promote development of abilities to discriminate among social partners and relationships with conspecifics (Bell et al. 2010). Moreover, in rats, juvenile social play increases neural plasticity in the medial prefrontal cortex later in life, suggesting that juvenile play might enhance long-term behavioral flexibility (Himmler et al. 2013). I note, however, that possible relationships between juvenile social play, brain development, and maternal territorial behavior in $U$. beldingi remain to be elucidated.

Individual differences in boldness and fearfulness are common in animals (Coleman and Wilson 1998; Webster et al. 2009; Bergvall et al. 2011; Dammhahn and Almeling 2012). It is possible that correlations between juvenile social play and yearling aggressive and vigilant behavior in $U$. beldingi are related to innate differences in boldness. Individuals who are especially bold might engage in juvenile play at high rates and also exhibit higher intensity in aggressive and vigilant behaviors as yearlings. However, I believe this unlikely. Correlations between juvenile play and yearling behavior in female $U$. belding $i$ were present only during gestation. If boldness were responsible for these correlations, they would be expected to persist across the entire reproductive period. Alternatively, social interactions in juvenile play might mediate increases in boldness among juveniles that persist to the beginning of the yearling active period, resulting in greater intensity in aggressive and vigilant territorial behavior early in the yearly reproductive cycle. Maternal experience might further shape aggressive and territorial behavior as the reproductive period progresses (Nunes 2014). Greater boldness is associated with higher degrees of aggression toward conspecific intruders in some animals (e.g., Carere et al. 2005), and social interactions with peers can modify boldness and fearfulness in individuals (e.g., Frost et al. 2007). However, the specific relationship between juvenile social play and boldness in $U$. beldingi remains to be determined.

Overall, results of this study indicate that juvenile social play in female $U$. beldingi is related to maternal territorial behavior and reproductive success as a yearling, and are consistent with the idea that juvenile social play behavior has benefits beyond the juvenile period in $U$. beldingi.

Acknowledgments I thank Roxxy Beltran Valencia, Alan ChanAlvarado, Michele Curtin, Chelsea Harmon, Michael Harrie, Matthew Heintz, Adelisa Legaspi, Natalie Lowry, Jonie Nguyen, Sara Ramsey, Valerie Salonga, Zaira Sanchez, and Jessica Weidenbach for their excellent assistance in the field. Allison Luengen provided valuable assistance with statistical analyses. This work was supported by the Faculty Development Fund at the University of San Francisco. 


\section{References}

Auger AP, Olesen KM (2009) Brain sex differences and the organization of juvenile social play behaviour. J Neuroendocrinol 21:519-525

Bekoff M (1972) The development of social interaction, play, and metacommunication in mammals: an ethological perspective. Q Rev Biol 47:412-434

Bekoff M (1988) Motor-training and physical fitness: possible shortand long-term influences on the development of individual differences in behavior. Dev Psychobiol 21:601-612

Bekoff M, Byers JA (1998) Animal play: evolutionary, comparative, and ecological processes. Cambridge University Press, Cambridge

Bell HC, Pellis SM, Kolb B (2010) Juvenile peer play experience and the development of the orbitofrontal and medial prefrontal cortices. Behav Brain Res 207:7-13

Bergvall UA, Schaepers A, Kjellander P, Weiss A (2011) Personality and foraging decisions in fallow deer, Dama dama. Anim Behav $81: 101-112$

Blumstein DT, Chung LK, Smith JE (2013) Early play may predict later dominance relationships in yellow-bellied marmots (Marmots flaviventris). Proc R Soc B 280:1-7

Burghardt GM (2005) The genesis of animal play: testing the limits. MIT Press, Cambridge

Burghardt GM (2011) Defining and recognizing play. In: Pellegrini AD (ed) The Oxford handbook of the development of play. Oxford University Press, Oxford, pp 9-18

Byers JA, Walker C (1995) Refining the motor training hypothesis for the evolution of play. Am Nat 146:25-40

Cameron EZ, Linklater WL, Stafford KJ, Minot EO (2008) Maternal investment results in better foal condition through increased play behavior in horses. Anim Behav 76:1511-1518

Carere C, Drent PJ, Privitera L, Koolhaas JM, Groothuis TGG (2005) Personalities in great tits, Parus major: stability and consistency. Anim Behav 70:795-805

Caro TM (1988) Adaptive significance of play: are we getting closer? Trends Ecol Evol 3:50-54

Coleman K, Wilson D (1998) Shyness and boldness in pumpkinseed fish: individual differences are context specific. Anim Behav 56:927-936

Cooke BM, Shukla D (2011) Double helix: reciprocity between juvenile play and brain development. Dev Cogn Neurosci $1: 459-470$

Dammhahn M, Almeling L (2012) Is risk taking during foraging a personality trait? A field test for cross-context consistency in boldness. Anim Behav 84:1131-1139

Fagen R (1981) Animal play behavior. Oxford University Press, Oxford

Fagen R, Fagen J (2004) Juvenile survival and benefits of play behaviour in brown bears, Ursus arctos. Evol Ecol Res 6:89-102

Fagen R, Fagen J (2009) Play behaviour and multi-year juvenile survival in free-ranging brown bears, Ursus arctos. Evol Ecol Res 11:1053-1067

Frost AJ, Winrow-Giffen A, Ashely PJ, Sneddon LU (2007) Plasticity in animal personality traits: does prior experience alter the degree of boldness? Proc R Soc B 274:333-339

Hass CC, Jenni DA (1993) Social play among juvenile bighorn sheep: structure, development, and relationship to adult behavior. Ethology 93:105-116

Himmler BT, Pellis SM, Kolb B (2013) Juvenile play experience primes neurons in the medial prefrontal cortex to be more responsive to later experiences. Neurosci Lett 556:42-45

Hol T, Van den Berg CL, Van Ree JM, Spruijt BM (1999) Isolation during the play period in infancy decreases adult social interactions in rats. Behav Brain Res 100:91-97
Holekamp KE (1984) Natal dispersal in Belding's ground squirrels (Spermophilus beldingi). Behav Ecol Sociobiol 16:21-30

Holekamp KE, Smale L, Simpson HB, Holekamp NA (1984) Hormonal influences on natal dispersal in free-living Belding's ground squirrels (Spermophilus beldingi). Horm Behav $18: 465-483$

Hrdy SB (1979) Infanticide among animals: a review, classification, and examination of the implications for the reproductive strategies of females. Ethol Sociobiol 1:13-40

Jenkens SH, Eshelman BD (1984) Spermophilus beldingi. Mamm Species 221:1-8

Kenagy GJ, Stevenson RD, Masman D (1989) Energy requirements for lactation and postnatal growth in captive golden-mantled ground squirrels. Physiol Zool 62:470-487

Kuehl HS, Elzner C, Moebius Y, Boesch C, Walsh PD (2008) The price of play: self organized infant mortality cycles in chimpanzees. PLoS ONE 3:e2440. doi:10.1371/journal.pone.0002440

Leedy MG, Vela EA, Popolow HB, Gerall AA (1980) Effect of prepubertal medial preoptic area lesions on male rat sexual behavior. Physiol Behav 24:341-346

Lewis KP (2000) A comparative study of primate play behavior: implications for the study of cognition. Folia Primatol 71:417-421

Maestripieri D, Ross SR (2004) Sex differences in play among western lowland gorilla (Gorilla gorilla gorilla) infants: implications for adult behavior and social structure. Am J Phys Anthropol 123:56-61

Meder A (1990) Sex differences in the behaviour of immature captive lowland gorillas. Primates 31:51-63

Meyer S, Weber J-M (1996) Ontogeny of dominance in free-living red foxes. Ethology 102:1008-1019

Morton ML, Gallup JS (1975) Reproductive cycle of the Belding ground squirrel (Spermophilus beldingi beldingi). Great Basin Nat 34:121-134

Morton ML, Maxwell CS, Wade CE (1974) Body size, body composition, and behavior of juvenile Belding ground squirrels. Great Basin Nat 34:121-134

Nunes S (2014) Maternal experience and territorial behavior in ground squirrels. J Mammal 95 (in press)

Nunes S, Zugger PA, Engh AL, Reinhart KO, Holekamp KE (1997) Why do female Belding's ground squirrels disperse away from food resources? Behav Ecol Sociobiol 40:199-207

Nunes S, Muecke E-M, Anthony JA, Batterbee AS (1999) Endocrine and energetic mediation of play behavior in free-living ground squirrels. Horm Behav 36:153-165

Nunes S, Muecke E-M, Ross HE, Bartholomew PA (2000) Food availability affects behavior but not circulating gonadal hormones in maternal Belding's ground squirrels. Physiol Behav 71:447-455

Nunes S, Muecke E-M, Lancaster LT, Miller NA, Mueller MA, Muelhaus J, Castro L (2004a) Functions and consequences of play behavior in juvenile Belding's ground squirrels. Anim Behav 68:27-37

Nunes S, Muecke E-M, Sanchez Z, Hoffmeier RR, Lancaster LT (2004b) Play behavior and motor development in juvenile Belding's ground squirrels (Spermophilus beldingi). Behav Ecol Sociobiol 56:97-105

Olioff M, Stewart J (1978) Sex differences in the play behavior of prepubescent rats. Physiol Behav 20:113-115

Pasztor TJ, Smith LK, MacDonald NK, Michener GR, Pellis SM (2001) Sexual and aggressive play fighting of sibling Richardson's ground squirrels. Aggress Behav 27:323-337

Paukner A, Suomi SJ (2008) Sex difference in play behavior in juvenile tufted capuchin monkeys (Cebus apella). Primates 49:288-291 
Pedersen JM, Glickman SE, Frank LG, Beach FA (1990) Sex differences in the play behavior of immature spotted hyenas, Crocuta crocuta. Horm Behav 24:403-420

Pellis S, Pellis V (2009) The playful brain. Oneworld Press, London

Pellis SM, Field EF, Smith LK, Pellis VC (1996) Multiple differences in the play fighting of male and female rats. Implications for the causes and functions of play. Neurosci Biobehav Rev 21:105-120

Poirier FE, Smith EO (1974) Socializing functions of primate play. Integr Comp Biol 14:275-287

Rho JR, Srygley RB, Choe JC (2007) Sex preferences in Jeju pony foals (Equus caballus) for mutual grooming and play-fighting behaviors. Zool Sci 24:769-773

Sharpe LL (2005) Play fighting does not affect subsequent fighting success in wild meerkats. Anim Behav 69:1023-1029

Sharpe LL, Cherry MI (2003) Social play does not reduce aggression in wild meerkats. Anim Behav 66:989-997

Sherman PW (1981a) Kinship, demography, and Belding's ground squirrel nepotism. Behav Ecol Sociobiol 8:251-259

Sherman PW (1981b) Reproductive competition and infanticide in Belding's ground squirrels and other animals. In: Tinkle DW, Alexander RD (eds) Natural selection and social behavior. Chiron, New York, pp 311-331

Sherman PW, Morton ML (1984) Demography of Belding's ground squirrels. Ecology 65:1617-1628

Sikes RS, Gannon WL, The Animal Care and Use Committee of the American Society of Mammalogists (2011) Guidelines of the
American Society of Mammalogists for the use of wild mammals in research. J Mammal 92:235-253

Špinka M, Newberry RC, Bekoff M (2001) Mammalian play: training for the unexpected. Q Rev Biol 76:141-168

Thompson KV (1996) Play-partner preferences and the function of social play in infant sable antelope, Hippotragus niger. Anim Behav 52:1143-1155

Twiggs DG, Popolow HB, Gerall AA (1978) Medial pre-optic lesions and male sexual behavior: age and environmental interactions. Science 200:1414-1415

van den Berg CL, Hol T, Van Ree JM, Spruijt BM, Everts H, Koolhaas JM (1999) Play is indispensable for an adequate development of coping with social changes in the rat. Dev Psychobiol 34:129-138

Ward C, Bauer EB, Smuts BB (2008) Partner preferences and asymmetries in social play among domestic dog, Canis lupus familiaris, littermates. Anim Behav 76:1187-1199

Webster MM, Ward AJW, Hart PJB (2009) Individual boldness affects interspecific interactions in sticklebacks. Behav Ecol Sociobiol 63:511-520

Wilson S (1974) Juvenile play of the common seal Phoca vitulina vitulina with comparative notes on the grey seal Halichoerus grypus. Behaviour 48:37-60 